\title{
Tsunami vulnerability assessment and its implications for coastal hazard analysis and disaster management planning, Gulf of Corinth, Greece
}

\author{
M. Papathoma ${ }^{1}$ and D. Dominey-Howes ${ }^{2}$ \\ ${ }^{1}$ Coventry Centre for Disaster Management, School of Science and the Environment, Coventry University, CV1 5FB, \\ Coventry, UK \\ ${ }^{2}$ Risk Frontiers, Department of Physical Geography, Macquarie University, Sydney, NSW 2109, Australia
}

Received: 19 June 2003 - Revised: 19 August 2003 - Accepted: 31 August 2003

\begin{abstract}
We apply a new tsunami vulnerability assessment method to two coastal villages in the Gulf of Corinth, Greece using the 7th February 1963 tsunami as a worse case scenario. In Akoli, $46.5 \%$ of all buildings are classified highly vulnerable (BV). Approximately, 26.3\% of all households are located within buildings with a High BV classification whereas $85 \%$ of all businesses are located within buildings with a High BV classification and $13.7 \%$ of the population is located within buildings with a High BV classification. In Selianitika, $28.8 \%$ of all buildings are classified with a High BV and $11 \%$ of all households are located within buildings with a High BV classification. Also $29.3 \%$ of all businesses and $33.4 \%$ of all services are located within buildings with a High BV classification and $6.7 \%$ of the population is located within buildings with a High BV classification. We estimate the minimum costs of a hypothetical tsunami with a wave run-up $\left(H(m)_{\max }\right)$ of $+5 \mathrm{~m}$. The results are considered significant because they have important implications for coastal risk assessment, resource allocation and disaster management planning.
\end{abstract}

\section{Introduction and background}

Greece has long been affected by tsunami and more than 160 events have been catalogued for the last 3500 years ( $\mathrm{Pa}$ padopoulos, 2001). Due to changes in the style and density of occupation and utilisation of the coastal zone within Greece, it has recently been suggested that the potential impacts of future tsunami are likely to be much greater than in the past (Dominey-Howes, 2002). It is therefore imperative to determine to what level selected coastal segments of Greece are at risk from, and vulnerable to, tsunami inundation and impacts. Scientists will be interested in the spatial and temporal distribution of tsunami events, their generative mechanisms and frequency-recurrence periods. Disaster and

Correspondence to: D. Dominey-Howes

(ddominey@els.mq.edu.au) emergency planners will be interested in determining maximum on-shore wave heights (vertical wave run-up) and the effects of wave flooding in terms of numbers and types of injuries and deaths, the disruption to normal activities, and the need for response, recovery and rehabilitation activities. Urban planners are likely to be concerned with understanding patterns of coastal flooding so as they may: (1) identify and develop appropriate land-use zones and (2) formulate and apply effective construction codes. Lastly, insurance and reinsurance companies are likely to be interested in frequency-magnitude relationships as they relate to determining risk and exposure and the establishment of suitable insurance premium levels.

Examination of published tsunami risk maps indicates that tsunami flood risk (and therefore damage to people and structures) is traditionally assumed to be uniform within the expected flood zone (e.g. Papadopoulos and Dermentzopoulos, 1998; Ganas et al., 2001). However, recently it has been shown that population and infrastructure within a given flood zone are not uniformly at risk (Papathoma, 2003; Papathoma et al., 2003). This is because risk, that is the probability of damage, is intimately related to vulnerability, which measures the potential for damage. Vulnerability in turn, is related to a series of parameters that include amongst others: the presence of on and off-shore protective barriers and flood defences, distance from the shore, depth of flood water, building construction standards, preparedness activities, socio-economic status and means, level of understanding and hazard perception and amount of warning and ability to move away from the flood zone.

Here, we report the results of an assessment of tsunami vulnerability for a coastal segment from the south shore of the Gulf of Corinth, Greece. This study has been undertaken for three reasons: (1) the Gulf of Corinth is one of the most tsunamigenic areas of Greece and has been identified as an area at risk from future tsunami occurrence; (2) we wished to apply a new tsunami vulnerability assessment method (hereafter referred to as the "Papathoma Method") to a new coastal area of Greece. This would then allow some as- 

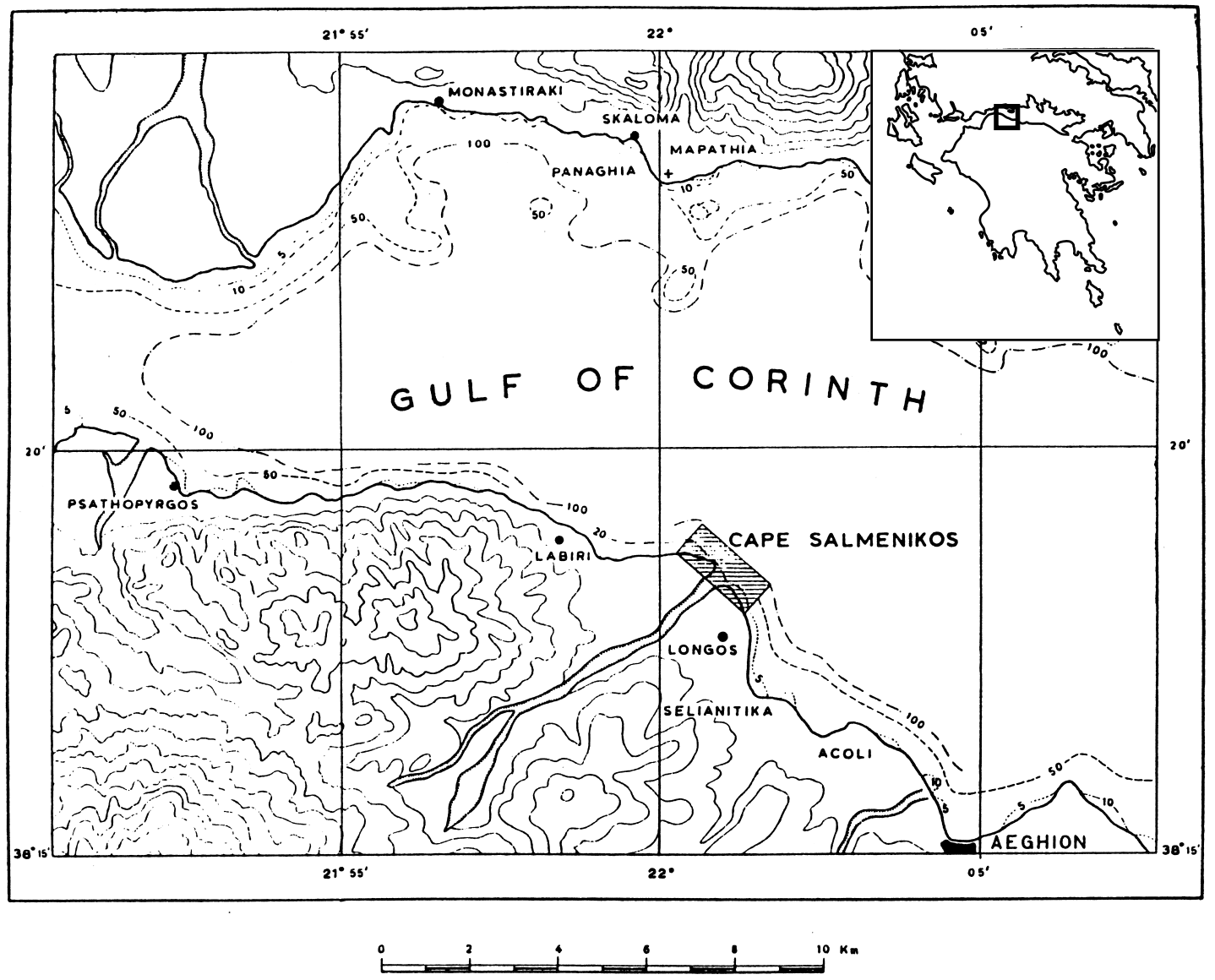

Fig. 1. Map of the field sites.

sessment of its ease of application in different coastal areas and whether vulnerability truly is spatially and temporally variable as previously reported and (3) the regional disaster plan under the code name "Xenokratis" does not contain any reference to tsunami events. Furthermore, to our knowledge, land-use planning and integrated coastal zone management strategies fail to consider the potential role of extreme hazards in coastal planning and management.

\section{The Gulf of Corinth and estimates of tsunami hazard probability}

The Gulf of Corinth is one of the most seismically active places in the world (Ambraseys and Jackson, 1997). The seismogenic belt that lies from Patras to Corinthos is $130 \mathrm{~km}$ long and $30 \mathrm{~km}$ wide (Koukouvelas, 1998). The Gulf of Corinth is a $100 \mathrm{~km} \times 25 \mathrm{~km}$ active asymetrical graben and is about $850 \mathrm{~m}$ deep (Papatheodorou and Ferentinos, 1997; Soter, 1998). The central part of this graben separates the alpine basement of central Greece from that of the Peloponnesos (Lekkas et al., 1998). The area is undergoing N-S extension and its geomorphology is the result of footwall uplift and hanging wall subsidence of a number of normal active faults (Papatheodorou and Ferentinos, 1997; Lekkas et al., 1996). Tsunamis that have been recorded in the Gulf of Corinth are usually associated with submarine sediment slides triggered either by heavy rainfall or seismic activity (Postma, 1995). This paper focuses on the coastline stretching from Aeghio (often referred to as Aeghion or Egio) westward as far as the village of Lambiri (Fig. 1). Firstly, we outline the tsunami hazard probability for the Gulf of Corinth; secondly, review the evidence for and impacts of the 7th February 1963 tsunami and thirdly, apply the "Papathoma Method" of tsunami vulnerability assessment to two villages on the coast using the 1963 tsunami as a worse case scenario.

The Gulf of Corinth has a long record of tsunami events. Some of them are listed in Table 1. Interestingly, it has been suggested that the spatial distribution of tsunami occurrences in the Gulf is focused in the west and decreases to the east (Papadopoulos, 2003). In fact, nine out of twenty tsunami (45\%), as well as the most powerful events, were recorded within the western part of the Gulf of Corinth. In contrast, the temporal distribution of the tsunami events is random. However, from the historical dataset of tsunamis in the Gulf, it has been possible to calculate the probability (return periods) for tsunami of different intensity. From an analysis of this dataset, tsunami with a maximum intensity or $K_{o}$ (on the Ambraseys-Sieberg six grade Intensity 
Table 1. Tsunami events in the Gulf of Corinth $(\mathrm{Y}=$ year, $\mathrm{M}=$ month, $\mathrm{D}=$ day. Generating cause: $\mathrm{ER}=$ submarine earthquake, $\mathrm{EA}=$ earthquake associated, $\mathrm{EL}=$ earthquake landslide, $\mathrm{ES}=$ earthquake generated submarine sediment slide, $\mathrm{GS}=$ gravitative marine slide, $K_{o}=$ Intensity). It is worth noting that no tsunami are reported for the period 373 BC to AD 552 and from AD 552 to AD 1402 . Data from Papadopoulos $(1998,2003)$

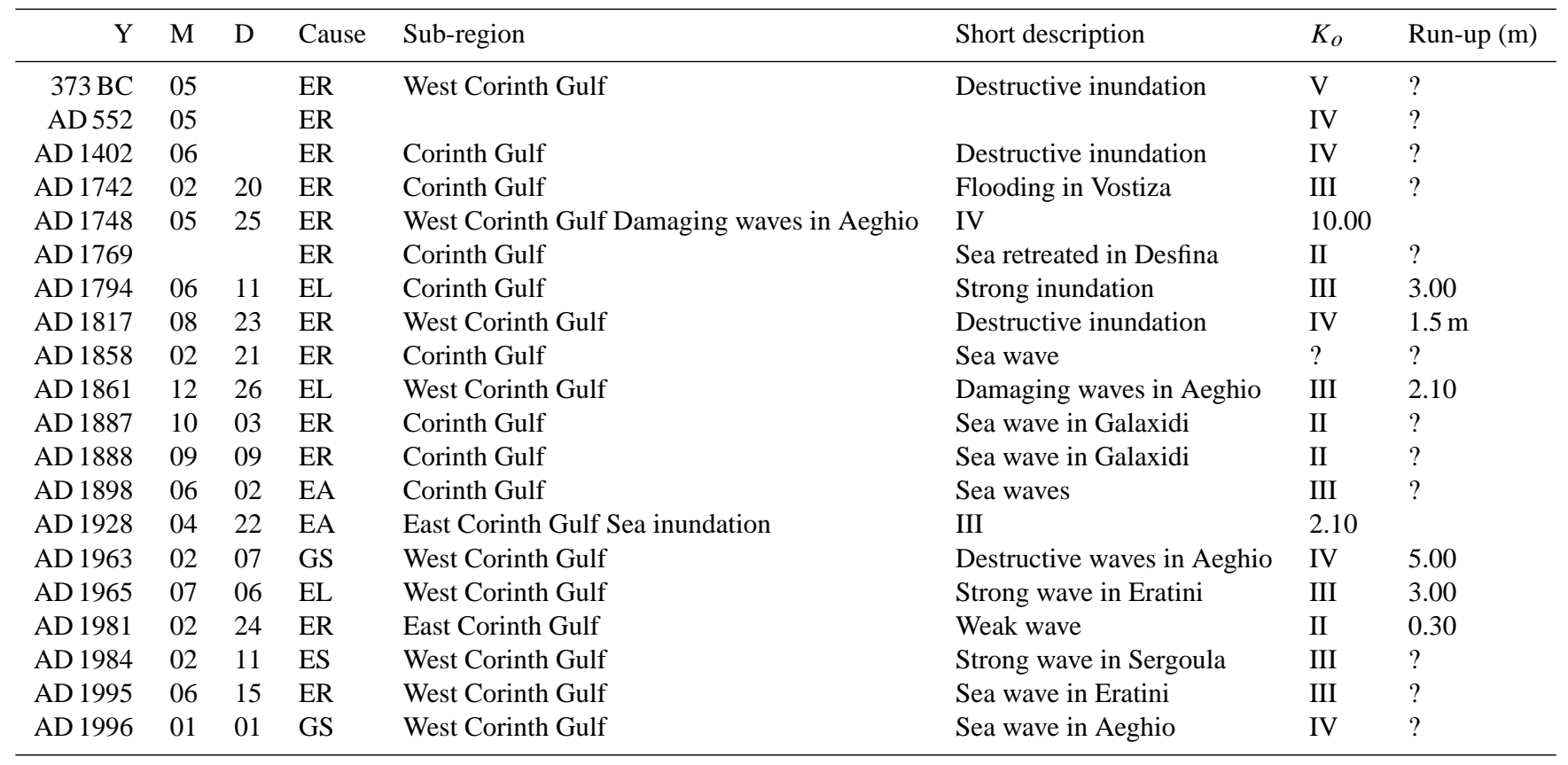

Scale, Ambraseys, 1962) of II or larger, occur on average, every 16 years. The return periods of tsunamis with intensity III or larger is 40 years, whereas tsunamis with intensity IV or larger occur on average, every 103 years $(\mathrm{Pa}-$ padopoulos, 2003). No tsunamis are reported within the historical dataset with intensities of V or VI. Of equal importance is an estimate of the likely wave height (or run-up) onshore for tsunami of intensity II, III and IV. Wave heights for all known tsunami were averaged and maximum wave heights $H(m)_{\max }$ determined for intensity $\left(K_{o}\right)$ II as $+1 \mathrm{~m}$, for $\left(K_{o}\right)$ III as $+2 \mathrm{~m}$, for $K_{o} \mathrm{IV}$ as $+4 \mathrm{~m}$, for $K_{o} \mathrm{~V}$ as $+8 \mathrm{~m}$ and for $K_{o}$ VI as $+16 \mathrm{~m}$ (Soloviev, 1978). Since these calculations are more than 20 years old and relate to tsunami from all over the world, using the data from Papadopoulos (2001) and Soloviev et al. (2002) which is the most complete dataset for our study area, we recalculate the mean $H(m)_{\max }$ for all tsunami ( $K_{o}$ II to IV) for the Gulf of Corinth alone. We therefore calculate that the $H(m)_{\max }$ for intensity $\left(K_{o}\right)$ II is $+0.3 \mathrm{~m}$, for $\left(K_{o}\right) \mathrm{III}$ is $+2.55 \mathrm{~m}$ and for $\left(K_{o}\right) \mathrm{IV}$ is $+5.5 \mathrm{~m}$. This follows the convention established in (Papathoma et al., 2003) and is useful because it permits direct comparison of tsunami impacts between different coastal segments within Greece.

Catalogues of historic tsunami were examined and those that impacted the study area were selected. By collecting information about these events it was possible to identify the extreme inundation zone as the area between the coastline and the contour of the highest ever documented/recorded wave. In our study area the inundation zone is defined as the area between the coastline and the $5 \mathrm{~m}$ contour since this is the run-up height calculated for the largest tsunami of $K_{o}$ IV. In our study, we ignore the tsunami of AD 1748 with a reported run-up of $+10.00 \mathrm{~m}$ even though this is the largest run-up recorded in the historical dataset. We exclude this event because there is insufficient data available concerning the exact locations affected by this tsunami; we are unable to verify the original sources thus making it impossible to crosscheck the accuracy of the run-up data and it has been clearly demonstrated that for the Greek region, data relating to historical tsunami events is notoriously unreliable (DomineyHowes, 2002). This correlates with the well documented tsunami of the 7th February 1963 (Papadopoulos, 2003; Papathoma, 2003; Galanopoulos et al., 1964). Therefore, the worse case scenario has a $H(m)_{\max }$ of $+5 \mathrm{~m}$ and correlates with a tsunami intensity of $K_{o}$ IV. The purpose of this paper is not to consider physical mechanisms or hydrodynamic characteristics of tsunami during generation, propagation or inundation, but to identify and quantify the vulnerability to a hypothetical tsunami achieving a $+5 \mathrm{~m}$ wave run-up in a deterministic way. Therefore, we do not consider factors such as tsunami source region, direction of wave approach, offshore bathymetry, coastal configuration, coastal geomorphology and hydrodynamic processes during inundation as these parameters are of concern more to theoretical modelers.

In the following section, we describe the tsunami of 7 th February 1963 and its effects since this represents the worse case tsunami event utilised within the present study. 


\section{The tsunami of 7th February 1963}

The tsunami of 7th February 1963 is a well-documented event generated by a submarine sediment slide triggered by a small earthquake. Building damage, coastal erosion and estimates of distances of horizontal inundation and wave height were recorded (Galanopoulos et al., 1964). In this paper, we use the term "run-up" since this is the correct term to describe this component of tsunami action. The tsunami wave occurred at 21:28 LT and affected several villages on the coast west of Aeghio. The places where the most damage and injuries are recorded were the port of Aeghio, and the coastal villages of Akoli, Selianitika (which includes part of Logos) and Lambiri. There are no official records from the local authorities concerning the actual number of houses damaged, nor of the nature of the damage. There is also no information on the exact location of the buildings affected nor on the costs of repair or reconstruction. However, the following paragraphs provide a description of the impacts of the 1963 tsunami on the four coastal villages most affected. It is worth noting that a numerical simulation of the 1963 tsunami by Koutitas and Papadopoulos (1998) reproduced very well the field observations of Galanopoulos et al. (1964).

In Aeghio (Fig. 1) the wave was of greatest intensity on the eastern part of the bay where horizontal inundation inland reached 30 to $40 \mathrm{~m}$ and the vertical wave run-up reached +3 ma.s.l. (metres above sea level). The wave reached the roof of the church of "Agios Nicholaos" and destroyed it. Two fishing boats were swept inland and damaged. A house and a tannery were flooded and two people were injured. At the centre of the bay the inundation of the water inland did not exceed the $+2 \mathrm{~m}$ contour and it caused no damage. The western side of the bay appears to have received a reflection of the initial wave, which had a run-up height of $+2 \mathrm{~m}$ a.s.l. Horizontal inundation was approximately 60 to $80 \mathrm{~m}$ inland. Six fishing boats were swept 10 to $12 \mathrm{~m}$ inland and two other fishing boats were found 30 to $40 \mathrm{~m}$ inland. According to local people, there were two waves, the initial one and the reflected one. There was also a noise before the waves struck.

In Akoli (Fig. 1) horizontal inundation at the eastern end of the bay was to a distance of more than $100 \mathrm{~m}$ from the shoreline. Traces of water were found on walls at a height of $+2.5 \mathrm{~m}$ a.s.l. indicating a minimum vertical wave run-up. The fence of a building was swept away and the person inside the building was injured. In the western part of the bay, the wave caused erosion of coastal sediments. The tsunami caused most damage in the centre of the bay where the wave height must have been $+4.5 \mathrm{~m}$ a.s.l. (Galanopoulos et al., 1964). Seaweed was found on the top of lemon trees $(2.5 \mathrm{~m}$ above the ground) at a distance of $90 \mathrm{~m}$ from the shoreline (Galanopoulos et al., 1964). Horizontal inundation was 250 to $300 \mathrm{~m}$ inland and the sea-water destroyed 30 lemon trees. The force of the tsunami caused the destruction of wooden floors within some of the houses. House contents were swept out to sea by the receding waters. At least $3000 \mathrm{~kg}$ of olive oil was lost and a $200 \mathrm{~kg}$ monolith was moved a distance of $4.5 \mathrm{~m}$ from its original position. At a distance of $120 \mathrm{~m}$ from the coastline many pebbles, fish and shells were found. Large quantities of cobbles and pebbles were deposited close to and inland of the beach. Parts of the beach were eroded and elsewhere a terrace $50 \mathrm{~cm}$ high and $10 \mathrm{~m}$ long was deposited by the tsunami. The volume of beach material that was eroded was estimated at 20 to $25 \mathrm{~m}^{3}$.

The wave had the greatest impact in the village of Selianitika (Fig. 1). The bay where the village is located is very shallow and the sea is only $-4 \mathrm{~m}$ and $30 \mathrm{~m}$ in depth at distances of 300 and $600 \mathrm{~m}$ from the coastline respectively. In the central part of the bay, horizontal inundation reached $40 \mathrm{~m}$ from the shoreline. The wave broke the doors and windows of several houses and swept away their contents. Deposits of sand and pebbles were found in some of the buildings. At 10 to $15 \mathrm{~m}$ from the coastline, vertical wave run-up reached $+3 \mathrm{~m}$ a.s.l. An iron container that weighed 1 tonne was moved horizontally a distance of $5 \mathrm{~m}$ and three fishing boats were swept $25 \mathrm{~m}$ inland. Inundation at the eastern end of the bay reached $40 \mathrm{~m}$ inland causing damage to houses. In fact, one of them totally collapsed. At the western end of the bay the inundation was 100 to $120 \mathrm{~m}$ inland and vertical wave height was estimated to be at least $+4 \mathrm{~m}$. Tsunami erosion of sediment uncovered the foundations of several houses. The coastal vineyards were damaged and 8 fishing boats were swept away and damaged. Between 6000 and $7000 \mathrm{~kg}$ of olive oil were lost and seven people were injured. Selianitika was struck by three waves and the first is reported to have been the strongest.

At Lambiri, the bay is relatively shallow and the depth of water only reaches $-2 \mathrm{~m}$ at 200 to $300 \mathrm{~m}$ from the shoreline. Horizontal inundation of water in the central part of the bay was to a distance of 50 to $110 \mathrm{~m}$. The tsunami is estimated to have had a vertical wave run-up of $+4 \mathrm{~m}$ a.s.l. The phenomenon began with a withdrawal of the sea to a distance of $30 \mathrm{~m}$ from the coast. The coastline was then struck by three waves. Two coastal houses and the facilities of a camping site suffered damage and fishing boats were swept inland and destroyed. A $150 \mathrm{~kg}$ fridge was moved a distance of $50 \mathrm{~m}$ and a $700 \mathrm{~kg}$ fridge was overturned. A $3 \mathrm{~m}$ stretch of the beach front was eroded.

At locations east and west of Cape Salmenikos (Fig. 1) the wave run-up height was estimated to have exceeded $+6 \mathrm{~m}$ a.s.l. since seaweed was found $100 \mathrm{~m}$ away from the coastline and at altitudes of at least $+2.20 \mathrm{~m}$ above the ground (Galanopoulos et al., 1964). However, the exact locations of these observations are not provided making it difficult to cross-check the information provided by the original authors.

Fortunately, only two deaths were caused by the tsunami due to its time of occurrence (late in the evening) and the fact that it occurred during the winter. It is interesting to wonder had the tsunami occurred during the day in summer time, whether many more casualties and fatalities would have been recorded due to the dense occupation of the near-shore coastal zone.

In this paper, a new tsunami vulnerability assessment methodology, the "Papathoma Method", is applied to Akoli 


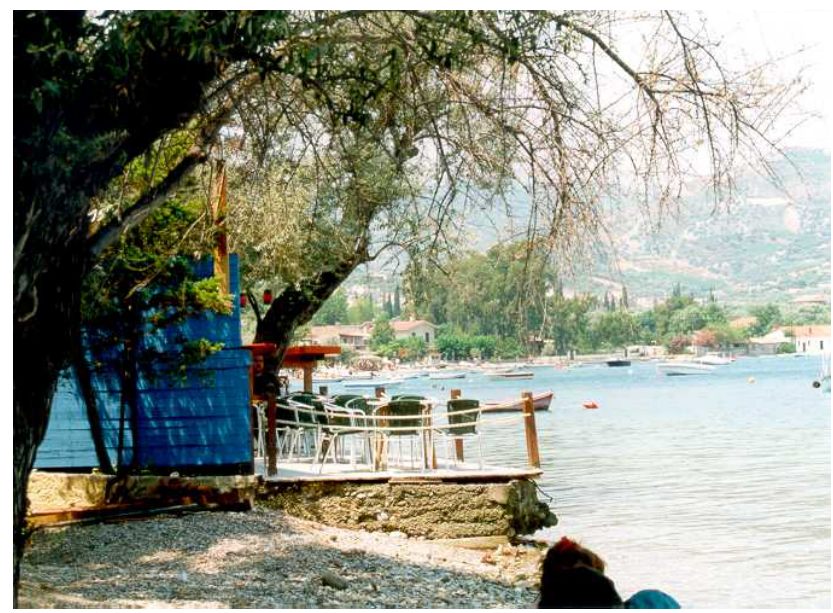

Plate 1. Café located on the coast of Akoli. Note how close it (and buildings on the far coast) are to the waters edge. Many of these buildings have no protection from coastal floods.

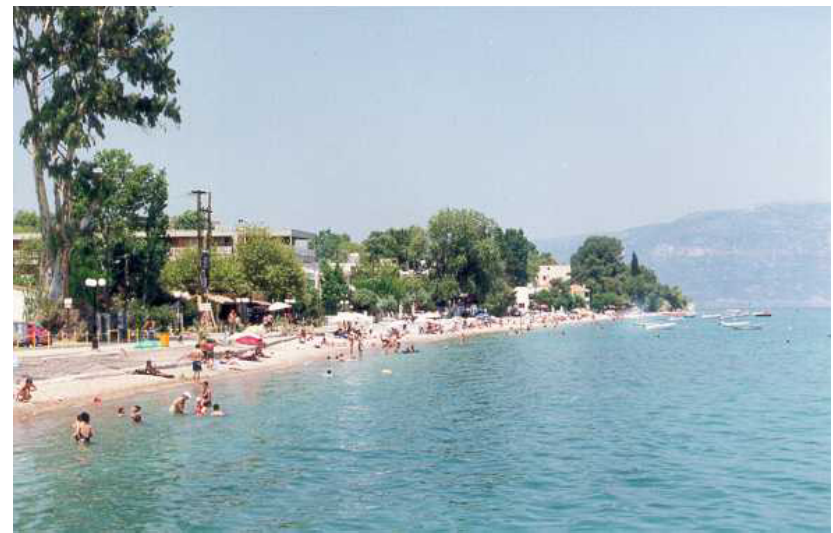

Plate 2. The beach at Selianitika in July 2001. During the summer period, the beach is densely populated. Once again, many of the buildings that fringe the coastline are extremely close to the waters edge and lack protective flood barriers.

and Selianitika only, due to their size and diversity of building use. Today, Akoli is a tourist resort that is extremely busy in the summer. The coastal area immediately adjacent to the shoreline is full of cafes and restaurants (Plate 1). The contemporary beach is either very narrow or in some places, does not exist at all. The houses that face the shoreline are not protected by fences or walls and the distance to higher ground is quite considerable since the village occupies a flat area. Selianitika is an important tourist place attracting families and elderly people as it is famous for its curative baths. Many hotels and restaurants are situated on the coastal plain just a few meters away from the present shoreline (Plate 2).

\section{Methodology}

It has recently been recognised that tsunami risk and vulnerability assessment has traditionally been rather simplistic (Papathoma, 2003; Papathoma et al., 2003). It has further been noted that previous studies do not consider vulnerabil- ity to be dynamic (Papathoma et al., 2003). It has also been realised that it is generally accepted that all buildings and spaces within a potential inundation zone are uniformly at risk. However, recent work has demonstrated that vulnerability actually has a very dynamic component dependent on a number of parameters (Papathoma et al., 2003). These authors illustrated their arguments by examining the tsunami vulnerability of Heraklio city, Crete Island, Greece. Here, the vulnerability assessment method developed in (Papathoma, 2003) is applied to our study villages within the Gulf of Corinth.

In the present study, the following methodological steps are undertaken:

A Identification of the Inundation Zone and Inundation Depth Zones

We select two of the coastal villages that were affected by the 1963 tsunami to undertake our tsunami vulnerability assessment because: (1) the area is at significant risk from future tsunami inundation (see Sect. 2 above); (2) the area was badly affected by the 1963 tsunami; (3) the villages affected by the 1963 event have developed significantly since the last event and (4) there are no specific tsunami disaster plans for the area.

The greatest wave height for the 1963 tsunami recorded in the area was $5 \mathrm{~m}$ (Galanopoulos et al., 1964). In this study the inundation zone is considered to be the area between the coastline and the $5 \mathrm{~m}$ contour, ignoring the direction of tsunami approach and the bathymetry of the seabed. This is not considered to be necessary because:

(a) it is not a specific wave that is simulated but a wave's impacts on the coastal community;

(b) in most tsunami-prone areas, historic events had different sources and;

(c) in most coastal areas it is hard to get data regarding the bathymetry at an appropriately detailed scale. Obtaining bathymetric data of this scale could be time consuming and very expensive. This would make the methodology unattractive for local authorities to use.

This study is interested in applying a method that is easy to utilise by different end-users and flexible enough to be applied in other places of the world. This study considers the identification of the inundation zone without taking into consideration the tsunami source and offshore bathymetry in order to be simple, easy and realistic. The run-up does not equal the tsunami height on the shore and the run-up heights will show variation along the coastline due to several factors (Camfield, 1994). Since the run-up cannot be calculated, the safest option for the identification of the potential inundation zone is to define it as the area between the coastline and the contour of the highest recorded tsunami. Therefore in an area where the highest recorded tsunami was $5 \mathrm{~m}$, the inundation zone will be the area between the coastline and 
Table 2. The criteria, their ranking and weight factor

\begin{tabular}{lc}
\hline Criteria & Weight factor \\
\hline Building material & 7 \\
Row & 6 \\
Surroundings & 5 \\
Condition of ground floor & 4 \\
Number of floors & 3 \\
Sea defence & 2 \\
Natural environment & 1 \\
\hline
\end{tabular}

the $5 \mathrm{~m}$ contour. It is understood that the depth of water during a tsunami will differ according to the ground elevation. Therefore, the inundation zone in each village will be divided into Inundation Depth Zones or IDZs on the basis of the topographic contours: High IDZ (ground elevation $0-2 \mathrm{~m}$ ), Medium IDZ (ground elevation 2-3 m), Low IDZ (ground elevation 3-4 m) and Very Low IDZ (ground elevation $4-5 \mathrm{~m}$ ). The IDZs are used as a background for the maps that display the spatial distribution of the vulnerability of individual buildings. It is understood that buildings located within the high IDZ will have to be the priority of the local authorities/ emergency planners etc. since the damage of the buildings will be more significant.

B Identification of factors that affect the vulnerability of buildings and people and collection of data

Field surveys of tsunami events such as the 1992 Flores tsunami, the 1993 Hokkaido tsunami and the 1994 Java tsunami (Maramai and Tinti, 1997; Tsuji et al., 1995; Shimamoto et al., 1995) demonstrate the importance of several characteristics of buildings that contribute to their vulnerability. These characteristics were identified and collected for each building within the potential inundation zone together with data concerning the population, building use and so forth. For further information on these factors, the generation of the primary database, the coverages digitized and the use of the Geographical Information System, readers are referred to (Papathoma et al., 2003). The empirical data were collected in July 2001. At this time of the year the villages are full of tourists that gather at the coastline during the day and evening.

C Calculation of the vulnerability of individual buildings within the inundation zone using a Multi criteria evaluation method

The data collected for each building and open space may be divided into three categories:

(a) quantitative (population, population density, number of households);

(b) qualitative (condition, building surroundings, natural environment, etc.) and (c) descriptive (e.g. land use)

The qualitative data are used for the calculation of the vulnerability of individual buildings. The first step is the standardisation of the raw data collected using the following formula:

Standardized score $\mathrm{I}=$ raw score $\mathrm{I} /$ maximum raw score Since the factors do not affect vulnerability equally, they have to be ranked according to their importance. The criteria are arranged in order of importance and a weight factor is applied (Table 2). The importance of the criteria is connected with the mitigation measures that may be taken. This is why the criteria that are concerned with the condition of the house are higher in the range of importance than the criteria that relate to the location. This is because it is felt that the condition of the house can change more easily and with less cost than its location. Relocation of buildings, construction of break waters and sea defences or coastal engineering works are frequently very expensive. On the other hand, reinforcement of buildings and protection with surrounding walls is easier and cheaper and may protect the building from other types of natural disasters.

The vulnerability of each building (BV) in the inundation zone is then calculated as follows:

$B V=(7 x a)+(6 x b)+(5 x c)+(4 x d)+(3 x e)+(2 x f)+(1 x g)$

Where:

(a) the standardised score that is related to the material of the building;

(b) the standardised score that is related to the row of the building;

(c) the standardised score that is related to the number of floors of the building;

(d) the standardised score that is related to the building surroundings;

(e) the standardised score that is related to the condition of the ground floor of the building;

(f) the standardised score that is related to the presence of sea defence in front of the building and;

(g) the standardised score that is related to the width of the intertidal zone in front of the building.

The Human Vulnerability (HV) of each building is calculated according to the following equation:

$\mathrm{HV}=\mathrm{BV} \times \mathrm{P}$ (where $\mathrm{P}=$ Population $)$

D Display of Building Vulnerability (BV) and Human Vulnerability (HV)

The spatial and temporal variation of building and human vulnerability may be displayed in a GIS map form. The results of our analyses are shown in Figs. 2 to 7. The database may also be used by various end-users and form a valuable tool for emergency planning, developing mitigation measures and insurance. Examples of such applications are shown in Fig. 8 and 9. 
Table 3. The number of buildings in each of the three building vulnerability $(\mathrm{BV})$ categories $($ High $=$ High $\mathrm{BV}, \mathrm{Medium}=\mathrm{Medium} \mathrm{BV}$, Low $=$ Low BV) within each of the Inundation Depth Zones (IDZs)

\begin{tabular}{cccccc}
\hline Akoli & High IDZ & Medium IDZ & Low IDZ & Very Low IDZ & Total BV \\
\hline High BV & 53 & 2 & 6 & 0 & $61(46.5 \%)$ \\
Medium BV & 35 & 13 & 8 & 4 & $60(45.8 \%)$ \\
Low BV & 1 & 2 & 4 & 3 & $10(7.7 \%)$ \\
\hline Total & $89(68 \%)$ & $17(13 \%)$ & $18(13.7 \%)$ & $7(5.3 \%)$ & $131(100 \%)$ \\
\hline Selianitika & High IDZ & Medium IDZ & Low IDZ & Very Low IDZ & Total BV \\
\hline High BV & 24 & 18 & 2 & 3 & $47(28.8 \%)$ \\
Medium BV & 35 & 49 & 21 & 8 & $113(69.3)$ \\
Low BV & 0 & 1 & 0 & 2 & $3(1.9 \%)$ \\
\hline Total & $59(36 \%)$ & $68(41.7 \%)$ & $23(14.1 \%)$ & $13(8.2 \%)$ & $163(100 \%)$ \\
\hline
\end{tabular}

Table 4. Diversity of building use within the two study villages and the permanent and maximum population

\begin{tabular}{lrr}
\hline & Akoli & Selianitika \\
\hline Total number of buildings* & 131 & 163 \\
Buildings with no use & 7 & 7 \\
Residential buildings & 104 & 95 \\
Households & 152 & 226 \\
Buildings with services & 0 & 3 \\
Buildings with businesses & 20 & 58 \\
Restaurants, cafes etc. & 14 & 22 \\
Shops & 2 & 2 \\
Hotels & 4 & 33 \\
Permanent population & 456 & 678 \\
Maximum population & 976 & 2232 \\
\hline
\end{tabular}

* An individual building may have many residential and/or business and services units within it. Therefore, the total number of separate units is greater than the total number of buildings.

\section{Results}

\subsection{The Building Vulnerability (BV)}

The village of Akoli is now dominated by residential buildings. There are also many restaurants/cafes (14) situated right at the waterfront. Figure 2 shows the distribution of $\mathrm{BV}$ in Akoli. Most of the buildings situated at the waterfront belong to the High BV category. Specifically, 61 or $46.5 \%$ of the total number of buildings belong to the High BV category (Table 3). Additionally, 60 or $45.8 \%$ of the buildings belong to the Medium BV category and 10 buildings or $7.7 \%$ belong to the Low BV category. The buildings that belong to the Low BV category are situated in the central part of the bay and the majority of them are located within the Low and the Very Low IDZ. Significantly, Table 3 shows that a total of 89 buildings (or $68 \%$ of the entire building stock of Akoli) are located within the High IDZ and of these, 53 buildings (or $60 \%$ ) are those classified as High BV.

In Selianitika today, there are 95 residential buildings, 33 hotels and 22 restaurants and cafes (Table 4). This is the most diverse and the most populated of the two study villages. In Selianitika (Fig. 3) the majority of the buildings are situated within the High (59 or $36 \%$ of all buildings) and Medium (68 or $41.7 \%$ of all buildings) IDZs respectively (Table 3). 47 or $28.8 \%$ of all buildings are classified as of High BV. 113 or $69.3 \%$ of all buildings are classified as of Medium BV. Figure 3 shows that there are two clusters of High BV buildings, one in the west-central part of the bay right at the waterfront and the other one in the east side of the bay. Only 3 or $1.9 \%$ of the buildings belong to the Low BV category.

\subsection{The Human Vulnerability}

Once an assessment of the vulnerability of each building within the inundation zone of each village has been undertaken, it is possible to assess the human vulnerability and show its distribution within the inundation zone (Figs. 4 and 5). The results of this assessment are summarised in Table 5. Table 5 shows that the majority of buildings in both villages have a Low HV classification. In Akoli, 18 or $13.7 \%$ of buildings have a High HV classification. In Selianitika, only 11 or $6.7 \%$ of buildings have a High HV classification. In Akoli, the High HV buildings are situated at the central and eastern part of the bay (Fig 4). In Selianitika, most of the High HV buildings are situated in the central part of the bay within easy reach of the roads that may be used during evacuation (Fig. 5).

The database can also provide information regarding the number of households that are located within buildings that are classified as of High, Medium and Low BV. These data are shown in Table 6 . Table 6 shows that the vast majority of the households in Selianitika (199 or $88.1 \%$ ) and the majority of households in Akoli (92 or 60.6\%) are located 
Table 5. Distribution of Human Vulnerability (HV) within the two study villages

\begin{tabular}{lrr}
\hline Human Vulnerability (HV) & Akoli & Selianitika \\
\hline High & $18(13.7 \%)$ & $11(6.7 \%)$ \\
Medium & $34(26 \%)$ & $29(17.9 \%)$ \\
Low & $79(60.3 \%)$ & $123(75.4 \%)$ \\
\hline
\end{tabular}

Table 6. Number of households located within buildings of High, Medium and Low BV classification

\begin{tabular}{lrr}
\hline Households in: & Akoli & Selianitika \\
\hline High BV & $40(26.3 \%)$ & $25(11 \%)$ \\
Medium BV & $92(60.6 \%)$ & $199(88.1 \%)$ \\
Low BV & $20(13.1 \%)$ & $2(0.9 \%)$ \\
\hline
\end{tabular}

\subsection{Other applications of the database}

within buildings with a Medium BV classification. However, a significant percentage of the households in Akoli and Selianitika (26.3\% and $11 \%$ respectively) are located within buildings with a High BV classification. In Selianitika, only 2 or $0.9 \%$ of the households are located in Low BV buildings whereas, in Akoli, the percentage of such households is larger at $13.1 \%$.

The database created for each village also contains information concerning the population density of individual buildings and open spaces for different times of the day and year. By using this information, maps showing the population density during the day in the summer in Akoli (Fig. 6) and in Selianitika (Fig. 7) may be produced. In this paper only the maps showing the population density during the summer are shown since the specific coastal villages do not have buildings or spaces that have high population density during the winter. Such maps could be used by rescue teams and emergency planners in order to pre-plan where the rescuers will focus their attention and efforts. Specifically, which buildings or open spaces are likely to contain dense concentrations of people (and therefore, possible casualties) during the emergency phase of a tsunami disaster.

\subsection{The Economic Vulnerability}

The number and percentage of businesses and services within each of the High, Medium and Low BV classifications are given in Table 7. Table 7 shows that in Akoli, the vast majority of the businesses (17 or $85 \%$ ) are located within buildings with a High BV classification. However, in Selianitika this percentage is lower ( $29.3 \%$ or 17 buildings) since the majority of the businesses $(68.9 \%)$ are located within buildings with a Medium BV classification. In Akoli, there are no services within the inundation zone. In Selianitika there are three services and one of them is located within a building with a High BV classification. Therefore, in Akoli, $85 \%$ of businesses are at significant risk of being adversely affected by tsunami inundation. Specifically, buildings, equipment, stock and products may all be damaged or destroyed. Such impacts may lead to major business interruption losses. Employees may have to be laid off thus increasing the impacts of the tsunami disaster beyond the initial emergency phase.
The primary database for Akoli and Selianitika also contains information that may be used by various end-users or stakeholders in order to produce maps that satisfy their particular needs. For example, local authorities might be interested in the height of the vegetation within the inundation zone and its spatial relationship to the location of vulnerable buildings in order to encourage the planting of trees in specific areas. Such coastal management may help to reduce horizontal flow velocities and hydrodynamic impacts on buildings and structures (such as bridges). Emergency planners may use the database in order to locate possible victims after an event. Figure 8 shows the location of one-floor buildings in Akoli that are at a distance of more than $50 \mathrm{~m}$ from the roads that lead to higher ground. There are 20 one-floor buildings (15.3\% of the total) that do not have direct access to the road network. Consequently, paramedic teams may go directly to these buildings since they are where casualties may be located. Finally, the database may be a useful tool to insurance and reinsurance companies that could use it in order to produce maps showing buildings that might experience content loss. The level of content loss would be determined by a number of factors that could include condition of the ground floor, location (row) from the coastline and the presence of protective barriers (Fig. 9). Figure 9 shows the buildings that are likely to experience content loss in Selianitika. There are 99 such buildings that constitute $60.7 \%$ of the total number of buildings within the potential inundation zone at Selianitika. With such a significant percentage of buildings likely to experience content loss, the level of insured risk may need reassessment.

In the present study, the application of the "Papathoma Method" shows clearly that the vulnerability of buildings to tsunami flooding is not uniform within the inundation zone. Vulnerability is a complex factor that depends on a number of parameters. Analyses of the spatial distribution of vulnerability enables local authorities and emergency planners to focus their limited resources in the most effective way. For example, it is obvious that the percentage of High BV buildings in Akoli (46.5\% of all buildings) is larger than the percentage of High BV buildings in Selianitika (28.8\% of

\section{Discussion}




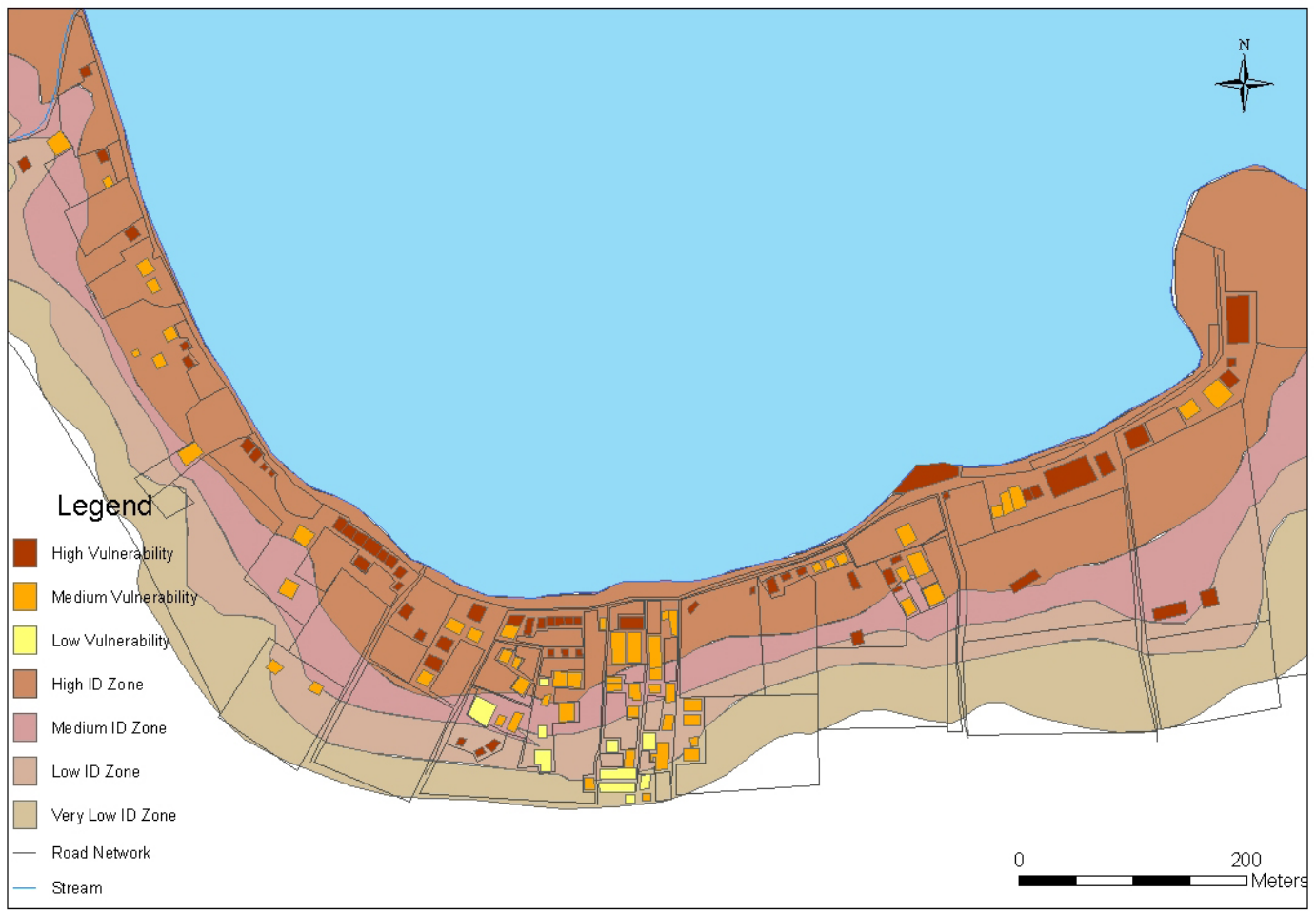

Fig. 2. Map to display the vulnerability of the buildings (BV) in Akoli.

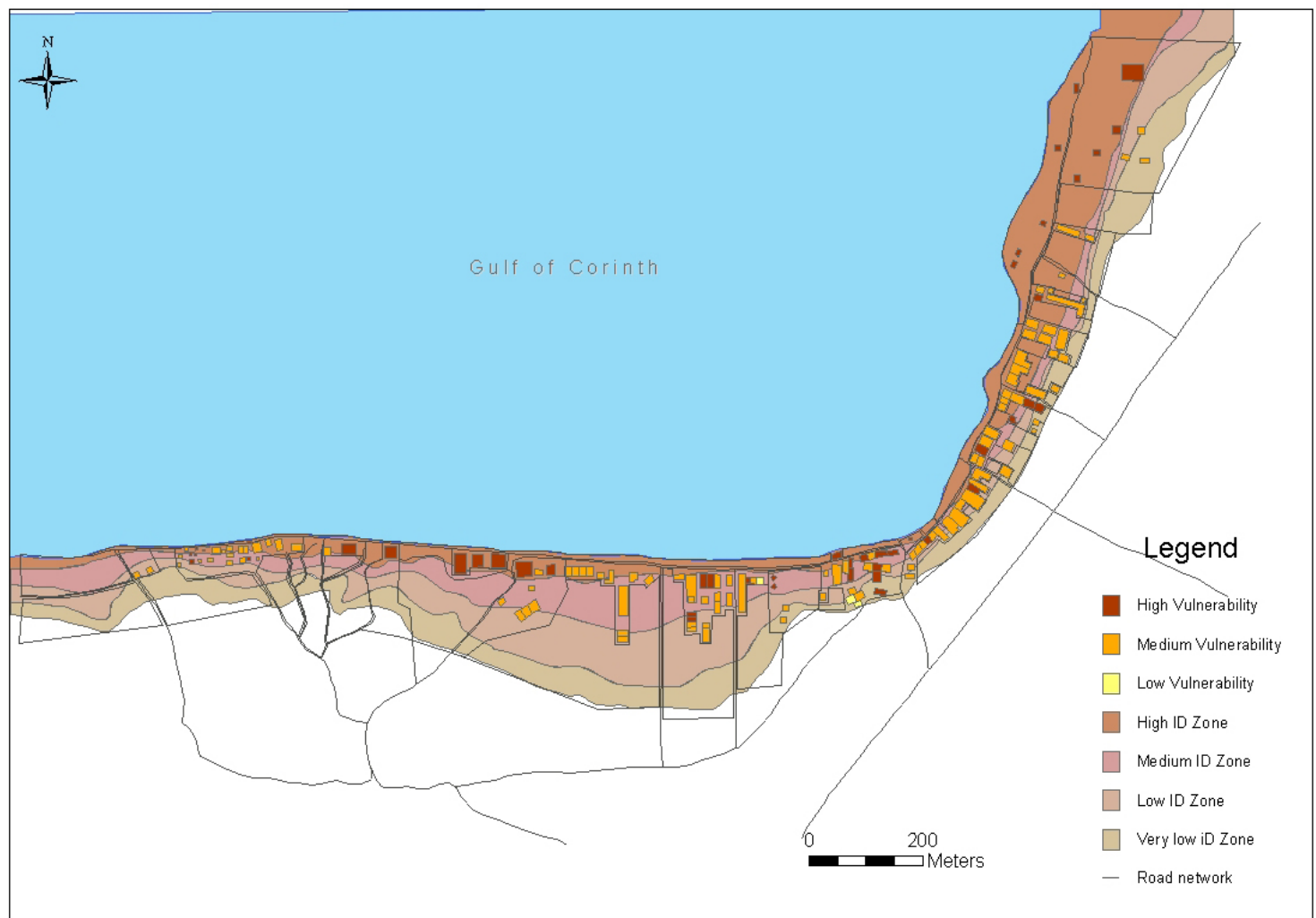

Fig. 3. Map to display the vulnerability of the buildings (BV) in Selianitika. 


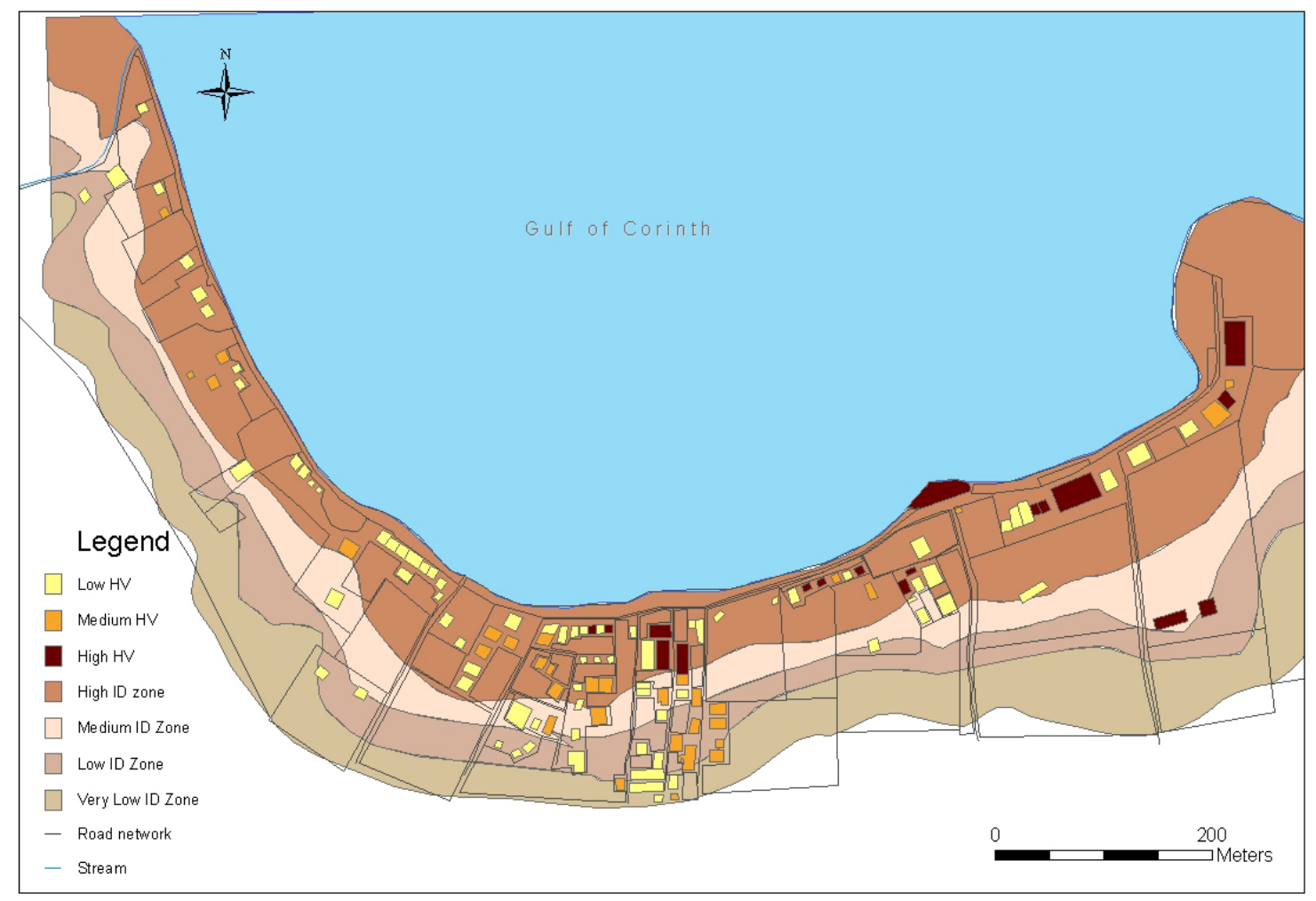

Fig. 4. Map to display the human vulnerability (HV) within individual buildings in Akoli.

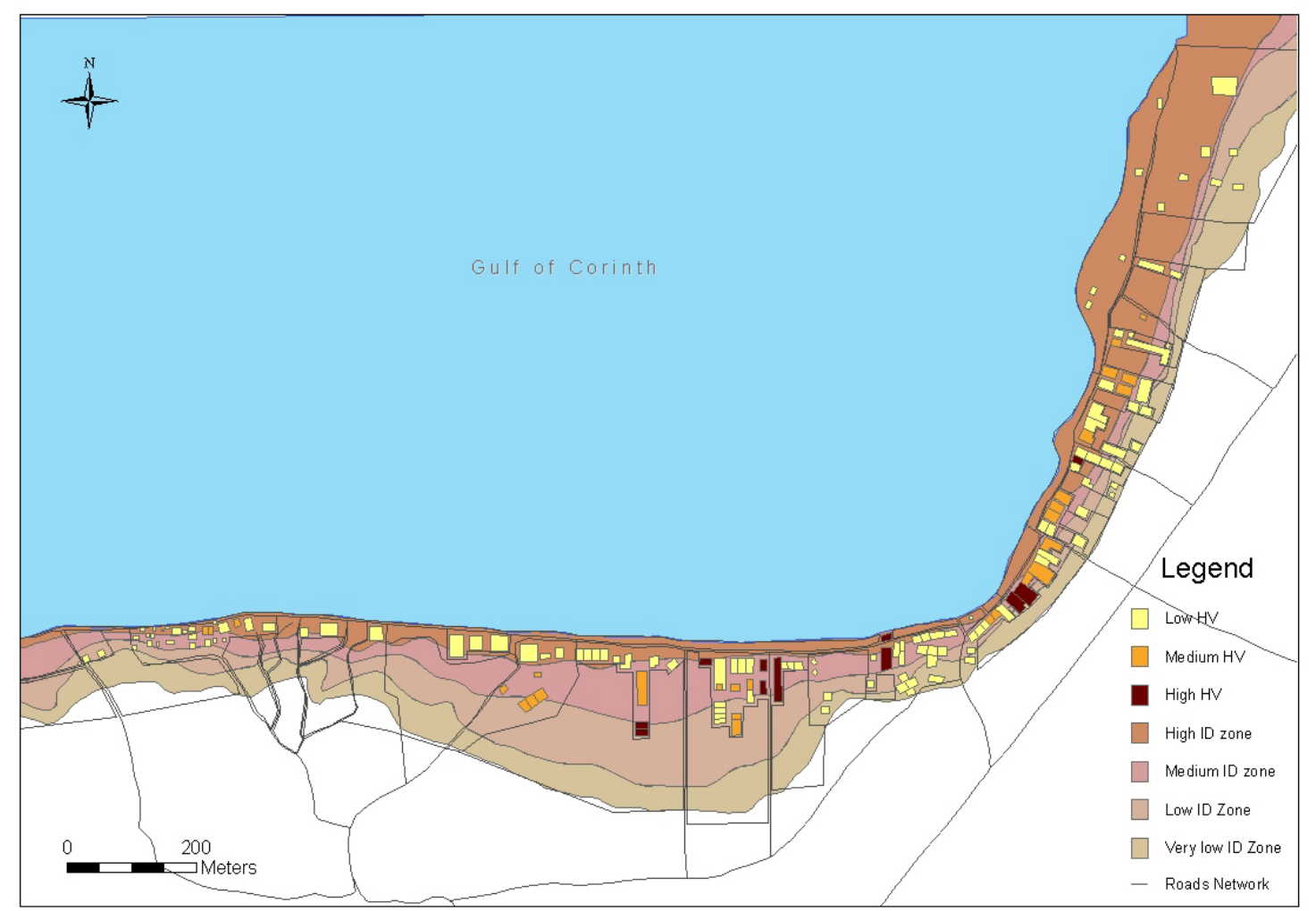

Fig. 5. Map to display the human vulnerability (HV) within individual buildings in Selianitika. 


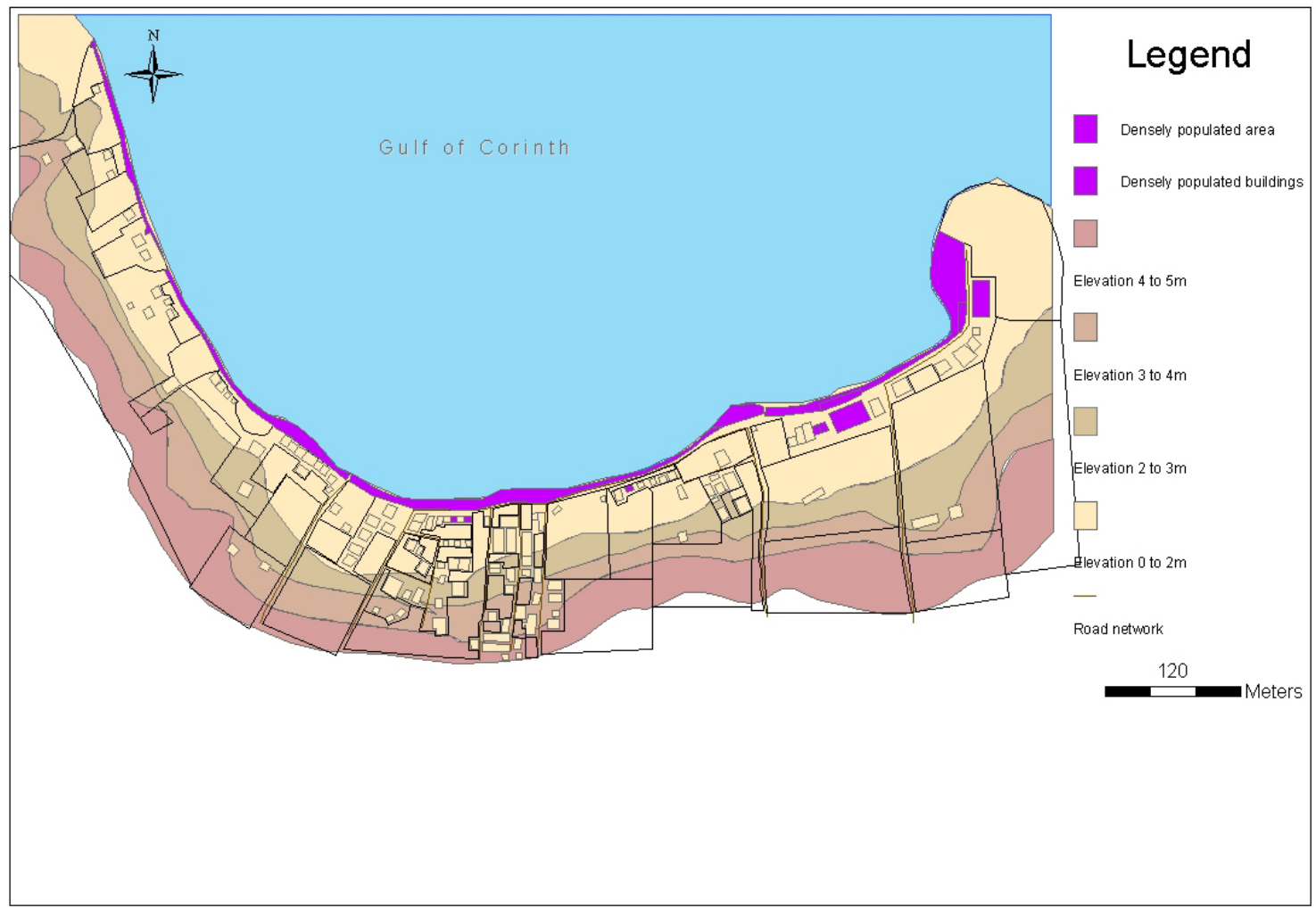

Fig. 6. Map to display the distribution of population in Akoli during the day in summer.

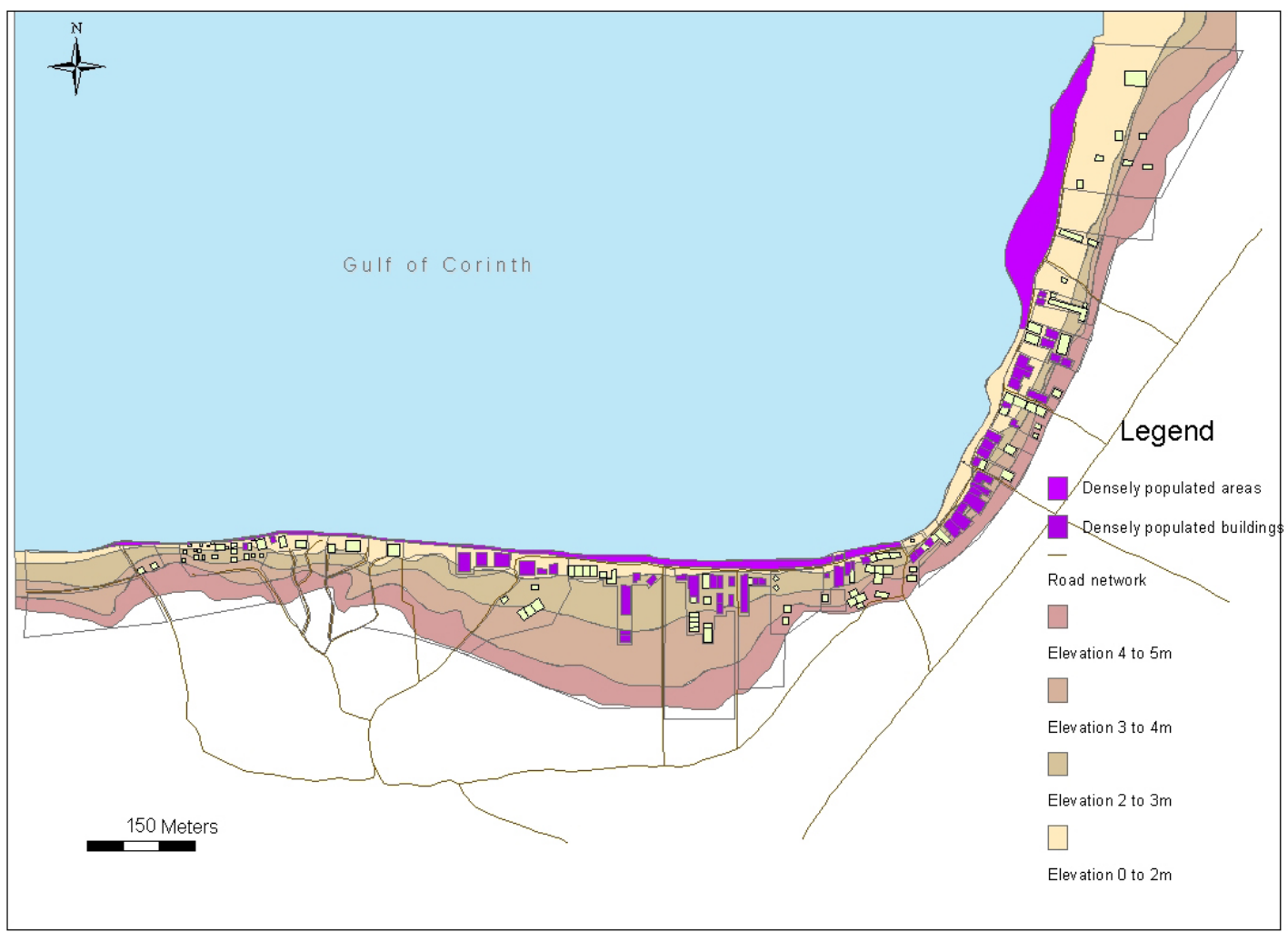

Fig. 7. Map to display the distribution of population in Selianitika during the day in summer. 


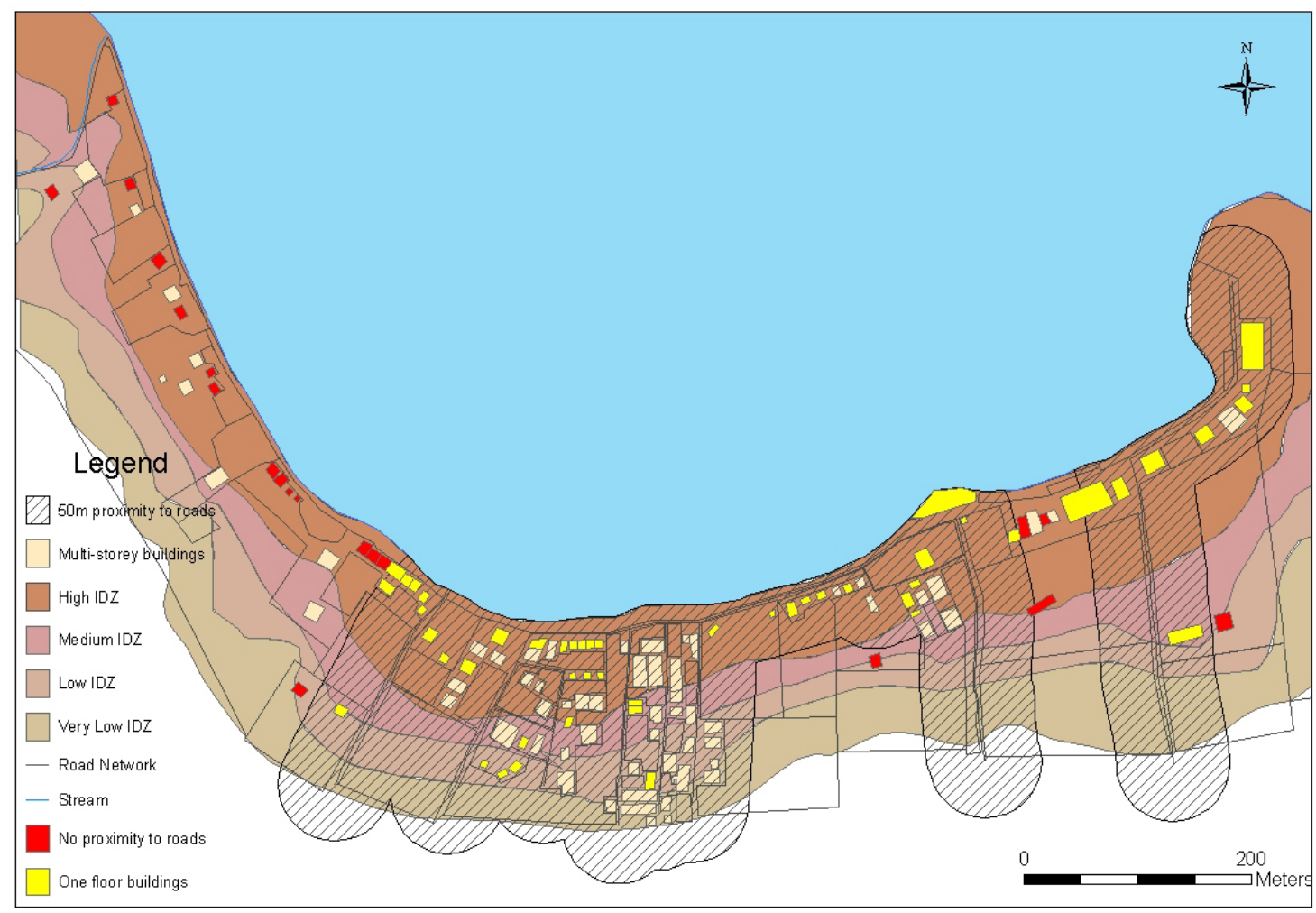

Fig. 8. Map to show the distribution of single (one)-story buildings that are at a distance of more than $50 \mathrm{~m}$ from the road network in Akoli. This map therefore, identifies those buildings from which it would be difficult to escape to safer (higher) ground.

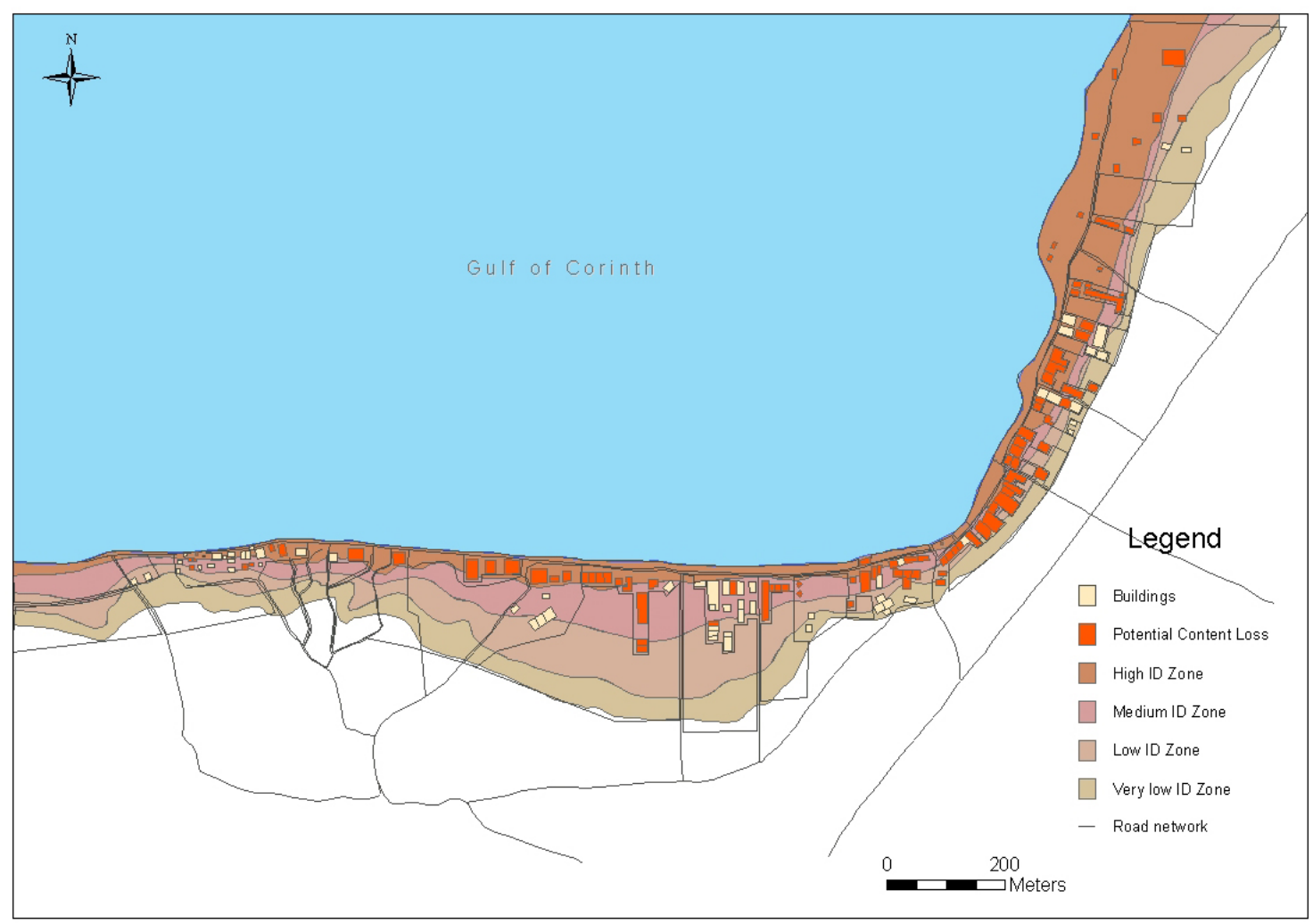

Fig. 9. Map to display the distribution of buildings within Selianitika that are likely to experience contents loss. 
Table 7. Number of businesses and services located within buildings of High, Medium and Low BV classification

\begin{tabular}{lllll}
\hline & Akoli & \multicolumn{3}{c}{ Selianitika } \\
\hline BV classification & Business & Service & Business & Service \\
\hline High BV & $17(85 \%)$ & 0 & $17(29.3 \%)$ & $1(33.4 \%)$ \\
Medium BV & $3(15 \%)$ & 0 & $40(68.9 \%)$ & $2(66.6 \%)$ \\
Low BV & 0 & 0 & $1(1.8 \%)$ & 0 \\
\hline
\end{tabular}

all buildings). Also, a larger percentage of households are located within High BV buildings in Akoli (26.3\%) than in Selianitika (11\%). Finally, the local economy of Akoli will suffer more since $85 \%$ of the businesses within the inundation zone are located within High BV buildings whereas the percentage of the businesses located within High BV buildings in Selianitika is $29.3 \%$. These results suggest therefore, that those agencies tasked with the responsibility of managing and responding to actual disasters and preplanning mitigative measures, should in the first instance focus their efforts and resources on targeting buildings, households and businesses located in High BV buildings in Akoli. The scale of this study and the spatial distribution of the results may enable various end-users to produce a series of maps that may be used for emergency planning, mitigation measures and house insurance issues.

By examining Tables 5, 6, 7 and 8 and the maps produced for the two study villages, it is possible to make a comparison between the damages and casualties that occurred in 1963 with the pattern of vulnerability based on data collected in 2001. Unfortunately, there were no lists of damage or property destruction after the tsunami of 1963. As such, no damage map could be produced nor could an accurate account of the number of houses that were damaged be given. However, a good description of the impact of the tsunami and its characteristics has previously been given (Galanopoulos et al., 1964). Valuable information concerning this event was collected in local newspaper archives. According to these newspapers, more that 10 residential houses collapsed, 2 people died and 7 were injured, animals and house contents were carried away by the waves, many houses were left empty with broken windows and doors (Erevna, 1963) and 25 households were compensated by the state (Foni tou Aeghiou, 1963). Although it is not possible to map the distribution of the damage of 1963, it has been determined that at least 10 residential houses completely collapsed and 25 households claimed compensation. It is easy to appreciate the potential effects of a similar event by looking at the results of the present study. There are 108 highly vulnerable buildings in Akoli and Selianitika (36.7\% of the total), which accommodate 65 households (approximately 17.2\%) and $34(43.5 \%)$ businesses. Finally, it is worth mentioning that the tsunami of 1963 occurred during a winter evening. It is clear that the impact would be much more serious if it were to have happened during the summer. Data concerning the value of buildings in the area could be used in order to "translate" the vulnerability maps into minimum estimates of cost. Data concerning compensation rates in 1963 were also hard to find. However, using the rates of compensation that were awarded by the Greek State Government following the Athens earthquake of 1999 , it is possible to estimate potential compensation costs for our study area following a major tsunami.

An approximate picture of the expected costs may be created based on the hypothesis that the highly vulnerable buildings within the study area will be destroyed during a tsunami flood. The hypothetical damage/costs for the area are given in Table 8. According to this rough calculation the costs of an event similar to that of 1963 would be at least 1.5 million Euros. Considering that the estimated costs do not include: compensation to families for the dead and injured, reconstruction costs, repair and reconstruction of infrastructure and communications, compensation to services, indirect impacts on tourism and so forth, it is easy to understand that the impact of an event at the present time would be significantly larger than that in 1963.

On the basis of the results presented herein, it is recommended that: (1) further research be undertaken in order to fully assess the probability of occurrence of tsunami with different $K_{o}$ intensities and $H(m)_{\max }$. This is of fundamental importance so that proper calculations of frequencyrecurrence may be completed. This is especially necessary for the Gulf of Corinth because the frequency of large tsunamis is not great. Furthermore, only one event is recorded for the period $373 \mathrm{BC}$ to $\mathrm{AD} \mathrm{1402;} \mathrm{(2)} \mathrm{more} \mathrm{de-}$ tailed "ground truthing" field survey assessments be completed around the shores of the Gulf of Corinth to fully identify those parameters that influence the vulnerability of people, property, businesses and infrastructure and (3) the "Xenokratis" plan should be re-written to take in to consideration the hazard posed by tsunami.

\section{Conclusions}

Greece is frequently affected by tsunami and the Gulf of Corinth has witnessed the impacts of large tsunami repeatedly during historical times. An analysis of the historical dataset indicates that tsunami with an intensity $\left(K_{o}\right)$ of IV recur, on average, every 103 years. The $H(m)_{\max }$ for intensity $K_{O}$ IV waves is $+5.5 \mathrm{~m}$. The last such event occurred 
Table 8. Estimated costs of a future hypothetical tsunami similar to the event of AD 1963 (achieving a flood run-up of $+5 \mathrm{~m}$ a.s.1.) for Akoli and Selianitika combined. Costs are in Euros and are based on compensation payments made following the 1999 Athens earthquake in different compensation classes. Data from http://www.minenv.gr

\begin{tabular}{lll}
\hline Impact of the tsunami upon: & Estimates costs & Euro \\
\hline 108 buildings & $108 \times 5869$ & 633852 \\
378 households within inundation zone & $378 \times 587$ & 221186 \\
34 businesses with minimum of 2 employees & $34 \times 2 \times 587$ & 39916 \\
65 households within destroyed buildings & $65 \times 293 \times 24$ & \\
\multirow{2}{*}{67 uninhabited residential units* } & $(24=$ mean rent allowance for 2 years) & 457080 \\
\hline Total & $67 \times 1467$ & 98289 \\
\hline
\end{tabular}

* The number of uninhabited residential units is the number of residential units that are likely to experience content loss minus, the High BV buildings that overlap. Therefore, here: $(99+76-108=67)$.

on the 7th February 1963. While another event of this magnitude may not be expected for many years, we undertake a new tsunami vulnerability assessment at two locations on the south shore of the Gulf of Corinth. Our reasons for undertaking such an analyses include: (1) the recent recognition that tsunami vulnerability is more complicated than hitherto considered; (2) the area affected by the 1963 tsunami has a much more developed urban landscape and infrastructure where the risk for tsunami impacts are considered much greater than in the past and; (3) that the existing emergency management plan (Xenokratis) does not consider tsunami disaster management.

In Akoli, $46.5 \%$ of all buildings are classified with a High BV. $26.3 \%$ of all households are located within buildings with a High BV classification. $85 \%$ of all businesses are located within buildings with a High BV classification. Finally, in Akoli, $13.7 \%$ of the entire population is located within buildings with a High BV classification. In Selianitika, $28.8 \%$ of all buildings are classified with a High BV. $11 \%$ of all households are located within buildings with a High BV classification. $29.3 \%$ of all businesses and $33.4 \%$ of all services are located within buildings with a High BV classification. Finally, in Selianitika, $6.7 \%$ of the entire population is located within buildings with a High BV classification.

The results of our study have important implications for many different end-users and stakeholders. Specifically, it would seem appropriate that those agencies tasked with tsunami disaster management ought to consider focusing their resources in the area of Akoli. In particular, businesses appear to be at significant risk to the impacts of a future tsunami event. Finally, recommendations include (1) further research that considers the occurrence of tsunami with different intensities; (2) detailed ground truthing assessments following tsunami events in order to identify those parameters that influence vulnerability and (3) the rewriting and improvement of "Xenokratis" emergency plan.

Acknowledgements. Dr. G. A. Papadopoulos is thanked for providing help during the data collection phase and Coventry University and the Coventry Centre for Disaster Management are thanked for providing the funding for this research.

\section{References}

Ambraseys, N. N.: Data for the investigation of seismic sea waves in the eastern Mediterranean, Bulletin of the Seismological Society of America, 52, 895-913, 1962.

Ambraseys, N. N. and Jackson, J. A.: Seismicity and strain in the Gulf of Corinth (Greece) since 1694, J. Earthqu. E., 1, 3, 433474, 1997.

Camfield F. E.: Tsunami effects on coastal structures, J. Coast. Res., Special Issue No 12, Coastal Hazards, 177-187, 1994.

Dominey-Howes, D. T. M.: Documentary and geological records of tsunamis in the Aegean Sea region of Greece and their potential application to risk assessment and disaster management, Nat. Hazards, 25, (3), 195-224, 2002.

Erevna (Local Greek Newspaper), 10/2/1963.

Foni tou Aegiou (Local Greek Newspaper), 14/2/1963.

Galanopoulos A. G., Delibasis N. D., and Komninaki, P. E.: A tsunami generated by an earth slump set in motion without shock, Annales Geologique des pays Helleniques (in Greek), 93-110, 1964.

Ganas, A., Nikolaou, E., Dermentzopoulos, Th., and Papadopoulos, G. A.: A GIS for tsunami risk mapping and management, in: NATO Advanced Research Workshop "Underwater Ground Failures on Tsunami Generation Modeling, Risk and Mitigation”, Istanbul, May 23-26, 2001, 249-252, 2001.

http://www.minenv.gr

Koukouvelas I. K.: The Egion Fault, earthquake related and long term deformation, Gulf of Corinth, Greece, J. Geodyn., 26, 2-4, 501-513, 1998.

Koutitas, C. G. and Papadopoulos, G. A.: Numerical simulation of the aseismically induced tsunami of 7 February 1963 in the western Corinthos bay, International Conference on Tsunamis, Paris, May 26-28, 247-254, 1998.

Lekkas, E. L., Lozios, S., Skourtsos, E., and Kranis, H.: Liquefaction, ground fissures and coastline change during the Egio earthquake (15 June 1995, Central-Western Greece). Terra Nova, 8, 648-654, 1996.

Lekkas, E. L., Lozios, S. G., Skourtsos, E. N., and Kranis, H. D.: Egio Earthquake (15 June 1995): An episode in the neotectonic 
evolution of Corinthiakos Gulf, J. Geodyn., 26, 2-4, 487-499, 1998.

Maramai, A. and Tinti, S.: Coastal effects and damage due to the 3rd June Java tsunami. in: Perspectives on Tsunami Hazard Reduction, edited by Hebenstreit, D., Kluwer Academic Publishers, 1-20, 1997.

Papadopoulos, G. A. and Dermentzopoulos, Th.: A tsunami risk management pilot study in Heraklion, Crete, Nat. Hazards, 18, 91-118, 1998.

Papadopoulos, G. A.: Tsunamis in the East Mediterranean: A Catalogue for the area of Greece and adjacent seas, Proceedings Join IOC-IUGG International Workshop Tsunami Risk Assessment Beyond 2000: Theory, Practice \& Plans, Moscow, 14 - 16 June, 2000, 34-43, 2001

Papadopoulos, G. A.: Tsunami hazard in the Eastern Mediterranean: strong earthquakes and tsunamis in the Corinth Gulf, Central Greece. Nat. Hazards, 29, 437-464, 2003.

Papatheodorou, G. and Ferentinos, G.: Submarine and coastal sediment failure triggered by the $1995, M_{S}=6.1 \mathrm{R}$ Aegion earthquake, Gulf of Corinth, Greece, Marine Geol., 137, 287-304, 1997.

Papathoma, M.: Assessing tsunami vulnerability using GIS with special reference to Greece, unpublished $\mathrm{PhD}$ thesis, Coventry University, pp. 290, 2003

Papathoma, M., Dominey-Howes, D. T. M, Smith, D. E., and Zong, Y.: Assessing tsunami vulnerability, an example from Her- akleio, Crete, Natural Hazards and Earth System Science, 3, 113, 2003.

Postma G.: Catastrophic sediment transport in the coastal zone of tectonically active regions: relevance to the destruction of $\mathrm{He}-$ like. Helike II, Ancient Helike and Aigialeia, Proceedings of the Second International Conference, Aigion, 1-3 December 1995, 417-441, 1995.

Shimamoto, T., Tsutsumi, A., Kawamoto, E., Miyawaki, M., and Sato, H.: Field survey report on tsunami disasters caused by the 1993 Southwest Hokkaido earthquake, Pur. A. Geoph., Special Issue: Tsunamis: 1992-1994. Their Generation, Dynamics and Hazard, 144, (3-4), 665-691, 1995.

Soloviev, S. L.: Tsunamis: the assessment and mitigation of earthquake and risk. UNESCO, 118-143, 1978.

Soloviev, S. L., Solovieva, O. N., Go, C. N., Kim, K. S., and Shchetnikov, N. A.: 2000 Tsunamis in the Mediterranean Sea 2000 B.C. - 2000 A.D., Kluwer Academic Publishers, 237 pp, 1978.

Soter, S.: Holocene uplift and subsidence of the Helike Delta, Gulf of Corinth, Greece, in: Coastal Tectonics, edited by Stewart, I. S. and Vita-Finzi, C., Geological Society, London, Special Publications, 146, 41-56, 1998.

Tsuji Y., Matsutomi, H., Imamura, F., Takeo, M., Kawata, Y., Matsuyama, M., Takahashi, T., and Harjadi, P.: Damage to coastal villages due to the 1992 Flores Island earthquake tsunami, Pur. A. Geoph., Special Issue: Tsunamis: 1992-1994. Their Generation, Dynamics and Hazard, 144, (3-4), 482-521, 1995. 